\title{
Random Amplified Polymorphic DNA (RAPD) Analysis of Human papilloma virus Isolated from Cervical Cancer Patient
}

\author{
Ayu Novita Trisnawati ${ }^{1}$, Annisa Fatharani ${ }^{2}$, Florence Clay Mora ${ }^{2}$, Yufri Aldi ${ }^{2}$, \\ Andani Eka Putra ${ }^{3}$, Yoke Kqueen Cheah ${ }^{4}$ and Marlina ${ }^{2 *}$
}

${ }^{1}$ Department of Biotechnology, Post Graduate Program, Andalas University, Padang, West Sumatera, Indonesia

${ }^{2}$ Faculty of Pharmacy, Andalas University, Padang, West Sumatera, Indonesia

${ }^{3}$ Departement of Microbiology, Faculty of Medicine, Andalas University, Padang,

West Sumatera, Indonesia

${ }^{4}$ Department of Biomedical Science, Faculty of Medicine and Health Sciences, Universiti Putra Malaysia, Selangor, Malaysia

*Corresponding author

\section{A B S T R A C T}

Cervical cancer prevalence is increasing every year. The major cause of this cervical cancer is the infection of high-risk Human

\section{Keywords}

Genetic

relationship,

Diversity, PCR,

Dendrogram, HPV

16, HPV 18

Article Info

Accepted:

04 March 2020

Available Online:

10 April 2020 papillomavirus (HPV) types. HPV variation is related to its ethnicity and geographical source. The objective of this study is to analyze HPV genetic diversity from the two Sumatran regions, Pekanbaru and Padang. Twenty DNA samples from cervical cancer patients were used in this study. HPV detection was carried out using MY09/11 primer. Positive HPV samples were amplified with OPO-6, OPO-18 and OPO-19 primer, and the dendrogram was constructed with UPGMA (Unweighted Pair Group Method with Arithmetic Mean) method. HPV was detected in fourteen DNA samples. PCR amplification by OPO primer showed multiple bands. The dendrogram results of the three primers, DNA samples divided into two groups $\mathrm{X}$ and $\mathrm{Y}$. Based on the dendrogram, HPV classified on genotypes and source origin. RAPD data describe HPV variance, but still need further analysis for comprehensive HPV diversity.

\section{Introduction}

The most common cancer among women in the world is breast cancer and followed by cervical cancer. There were an estimated 570,000 new cervical cancer cases and 311,0000 deaths worldwide in 2018 (Bray et al., 2018). Almost $90 \%$ of cervical cancer 
deaths occurred in developing parts of the world and $144.400(54 \%)$ of cervical cancer cases occurred in Asia (Torre, et al., 2015). In Indonesia, cervical cancer is the second most frequent cancer disease among female between 15 and 44 years old. In 2012-2013 cervical cancer ranks first in the most caused of women death with 98.692 cases. Current estimates in 2017 indicate that every year 20.928 of 93.15 million women population are diagnosed with cervical cancer with the mortality rate of 9.498 (ICO, 2017).

The main cause of cervical cancer is Human papillomavirus infection. HPV is sexually transmitted by a person who already infected with this virus (Dunne and Markowitz, 2006). Epidemiology study shows that the main agent in cervical cancer is HPV is type 16, 18, 31, and 45 which includes the High-Risk types of HPV. Epidemiology also proved that HPV type 16 and 18 are the major course of cervical cancer (Serrano et al., 2018).

Our previous study has been reported research with identification and isolation of HPVs from cervical cancer patients in Dr M. Djamil Padang Hospital and Achmad Arifin Pekanbaru hospital. HPV type 16, 18, 45, and 52 were found with percentages of $28.5 \%$, $40.4 \%, 7.1 \%$, and $2.3 \%$ in the 42 samples (54\%) of 72 samples that obtained from Formalin-fixed paraffin-embedded (FFPE), patient cervical smears, and patients cervical cancer fresh tissues.

The study shows that HPV type 18 is the most dominant type compared to the other three types of the virus (Marlina et al., 2016). The HPV studies then continued about its protein that causes the highest risk against cervical cancer which are E5, E6, and E7.

A study by Sopianti et al., (2016) showed that 9 out of 15 samples $(60 \%)$ are detected as E5 gene HPV type 18 and there is no molecular variation in its sequence with $100 \%$ homologous equations.

The variation HPV genetic has a minor correlation with geographical source and ethnic (Heinzel et al., 1995). Variant and HPV subtypes are having an important role as a guide to understand HPV evolution and to know its genomic intermediate which related to the difference of each type. DNA sequence variation in epidemiology study is used as a marker to track the virus deployment in population and to see the relation of its genomic and phenotypic diversity, as the biologically or pathologically difference for example. Research about DNA is also given a chance to know about the relation of genomic diversity with disease severity (Wuriningtyas, et al., 2014).

One of the approaches to know about genomic diversity is by using Random Amplified Polymorphic DNA (RAPD) method, which is a modification of the Polymerase Chain Reaction (PCR) method. RAPD method is more simple than the conventional or nested PCR method and there is no need for sequencing step (Welsh and McClelland, 1990). The objective of this study is to see the level of HPV genomic diversity between samples from two Sumatran regions, Padang and Pekanbaru, by constructing its dendrogram.

\section{Materials and Methods}

\section{Isolation of Human papillomavirus DNA}

HPV DNA which uses in this study carried out as our previous study (Marlina, 2016). Cervical biopsy from Arifin Ahmad Hospital Pekanbaru and M. Djamil Hospital, Padang was isolated using DNA Extraction Kit gSYNCTM. Isolation of DNA was done according to the protocol of the kit being used. 


\section{HPV identification and genotyping}

Identification HPV had done by using consensus primer MY09/11 primer (forward 5'-CGT CCM ARR GGA WAC TGA TC-3' and reverse 5'-GCM CAG GGW CAT AAY AAT GG-3') with 450bp of product length (Erhart et al., 2016), while HPV genotyping had done using specific primer for HPV 16 (forward 5'GTC AAA AGC TGT GTC CT-3' and reverse primer 5' CCA TCC ATT ACA TCC CGT AC-3') and HPV 18 (forward primer 5'TCG TTT TCT TCC TCT GAG TCG CCT-3' and reverse primer 5'CCG AGG ACG ACA GGA ACG ACT-3') (Marlina, 2016).

PCR cocktail were prepared for $25 \mu \mathrm{L}$ volume, which consist of $2 \mu \mathrm{L}$ isolate sample, 12,5 $\mu \mathrm{L}$ 10X PCR buffer (100 mmol 1-1 Tris$\mathrm{HCl}, 35 \mathrm{mmol} 1-1 \mathrm{MgCl} 2,750 \mathrm{mmol} 1-1 \mathrm{KCl}$, $\mathrm{pH} 8,8$ ), 2,5 $\mu \mathrm{L}$ dNTPs (Promega, Madison, USA), $1 \mu \mathrm{L}$ forward primer, $1 \mu \mathrm{L}$ reverse primer, 0,2 $\mu \mathrm{L}$ Taq DNA polymerase (Promega, Madison, USA), 17,8 $\mu \mathrm{L}$ sterile distilled water. The PCRs were conducted using the Mastercycle Personal ${ }^{\circledR}$ (Eppendorf, Germany) with PCR cycling conditions: hot start $94^{\circ} \mathrm{C}$ for $2 \mathrm{~min}, 40$ cycles of denaturation $94^{\circ} \mathrm{C}$ for $30 \mathrm{sec}$, annealing $50^{\circ} \mathrm{C}$ for $1 \mathrm{~min}$, extension $72^{\circ} \mathrm{C}$ for $1 \mathrm{~min}$, and final extension $72^{0} \mathrm{C}$ for $10 \mathrm{~min}$.

The PCR products were electrophoresed using a $1.5 \%$ agarose gel in $1 \times$ TBE buffer, stained with ethidium bromide $(0.5 \mathrm{~g} / \mathrm{ml})$ and photographed used gel documentation system transilluminator UV (Alpha Innotech®). A low DNA mass ladder was used as a base-pair molecular weight pattern (DNA ladder $100 \mathrm{bp}$ Thermo scientific $\left.{ }^{\circledR}\right)$

\section{RAPD-PCR parameters}

Three arbitrary primers from Operon Technologies Inc. (Alameda, CA, USA) were used for amplification of random DNA markers to reveal the genetic diversity among Human papillomavirus populations. Details of the primers used in the present study are given in Table 1. The DNA was amplified through RAPD according to Williams et al., (1990). Approximately $2 \mu \mathrm{L}$ of genomic DNA of HPV was used. The RAPD reaction was performed in a Mastercycle Personal ${ }^{\circledR}$ (Eppendorf, Germany) for 1 cycle at $96^{\circ} \mathrm{C}$ for $5 \mathrm{~min}$, followed by 40 cycles of $94^{\circ} \mathrm{C}$ for 1 $\min , 36^{\circ} \mathrm{C}$ for $1 \mathrm{~min}$ and $72^{\circ} \mathrm{C}$ for $2 \mathrm{~min}$, respectively. The final amplification cycle included 7 min extension at $72^{\circ} \mathrm{C}$.

Separations for band fragments as the result of amplification were made with horizontal electrophoresis with agarose gel $1.5 \%$ in TrisBoric acid EDTA (TBE) solution at 68 volts until the DNA migration reached up to $2 / 3$ of the length of the gel. The gel then stained with ethidium bromide (EtBr). Gene ruler 1 $\mathrm{kb}$ ladder (Thermo scientific $囚$ ) was used as a standard to determine the size of DNA fragments.

\section{RAPD data analysis}

Gel documentation acquired was analysed using BioNumerics version 6.6 software (Applied Maths, Kortrijk, Belgium), for cluster analysis via Unweighted Pair Group Mathematical Averaging (UPGMA) and Dice Coefficient. Dendrograms generated from different DNA fingerprinting methods were evaluated as single and as composite dendrograms, to find the most meaningful clustering.

\section{Results and Discussion}

A total of 20 DNA samples was carried from our previous study was used for RAPD Analysis (Marlina et al., 2016). The most common molecular diagnosis for HPV is using MY09/11 or GP5+/6+ primer. In this 
study, we use MY09/11primer for detection of HPV existence in our samples. HPV DNA was identified in 14 samples $(70 \%)$. The positive result determined based on the 450 bp band appear on the agarose gel, shown in Figure 1. The MA.114.05, MA.092.15, and MA.093. 17 samples were negative because of no band on the gel.

Compared with our previous study, all of the selected samples was positive HPV by using GP+/5+ primer (Marlina et al., 2016). A study of HPV detection using primers MY09/MY11 and GP5+/GP6+ in also cervical patients by Venceslau et al., (2014) observed a greater number of positive samples using GP5+/GP6+ primer when compared to MY09/ MY11. From 27 samples, 30\% were positive for HPV. HPV DNA was found in $15 \%$ and $30 \%$, using MY and GP pair of primers, respectively. From these, $15 \%$ were detected by both methods, and $30 \%$ only by GP pair.

Another study by Shikova et al., (2009) examined 54 cervical specimens obtained from cytologically normal women and women with low- and high-grade lesions of the cervix for the presence of HPV DNA by PCR using consensus and type-specific primers to determine if HPV detection varies when different primer sets are used. Both MY09/MY11 and GP5+/GP6+ consensus primer sets, exhibited approximately equal sensitivity, as defined by the ability to detect HPV DNA. $27.8 \%$ and $25.9 \%$ of samples were HPV positive in PCR using MY09/MY11 primers and GP5+/GP6+ primers, respectively. GP5+/GP6+ primer failed to detect HPV DNA in 1 sample found HPV positive by MY09/MY11.

In a study by Qu et al., (1997) about the comparison between MY09/MY11 and GP5+/GP6+ in PCR detection of HPV, 280 samples were evaluated in the and HPV DNA was detected in $45.2 \%$ and $42.8 \%$ of the samples by using the MY pair and the GP pair sets, respectively. These results indicate that although the MY and GP pairs identified nearly equivalent prevalence of HPV in a set of clinical samples, differences in the detection of specific types and infections with multiple types were found. Differences in the sensitivities and characteristics of the PCR systems for the detection of HPV within clinical samples should be considered when comparing data between studies and/or in designing new studies or clinical trials.

GP5+/6+ and MY09/MY11 primers able to amplify a wide spectrum of HPV genotypes in cervical cancer patients, it is possible that some variant of HPV types in the samples are might not be generally detected. Both primers have each other's strengths. The GP5+/6+ primer set was better at detecting low viral copy numbers, while the MY09/11 primer set was better at detecting co-infections. The use of a single primer set might lead to underestimating HPV infection rates (Camargo et al., 2011).

HPV genotype prevalence in this study is shown in Table 2. HPV 18 was the most common genotype detected $6(43 \%)$, followed by HPV 16 (36\%). Multiple infection HPV 16 and HPV 18 observed in MA.060.10 and MA.054.14 sample. A study in Shandong Province, China reported $62.8 \%$ samples to have single infections and others get multiple with two or more genotype infection (Jiang et al., 2019). Multiple high-risk HPV infection also was observed in $10 \%$ specimen at Apulia, South Italy Region (Coscia et al., 2015).

A study among women with normal and abnormal cervical cytology presenting in a tertiary gynaecology referral clinic in Ethiopia declare the most frequent genotypes identified were HPV16 (44.1\%), followed by HPV35 
and HPV45 (each 6.2\%), HPV31 (4.4\%), HPV56 (3.7\%), HPV18 and HPV59 (each

3.1\%), HPV58 (2.5\%) and HPV39 (1.9\%) (Wolday et al., 2018).

Table.1 RAPD primer name and sequence

\begin{tabular}{|c|c|c|c|c|}
\hline No & $\begin{array}{c}\text { Locus } \\
\text { name }\end{array}$ & $\begin{array}{c}\text { Primer Sequence } \\
\left(\mathbf{5}^{\prime}-\mathbf{3}^{\prime}\right)\end{array}$ & $\mathbf{\% G C}$ & $\mathbf{T m}\left(\mathbf{(}^{\mathbf{C}} \mathbf{)}\right.$ \\
\hline $\mathbf{1}$ & OPO-06 & CCACGGGAAG & 70 & 46 \\
\hline $\mathbf{2}$ & OPO-18 & CTCGCTATCC & 60 & 40 \\
\hline $\mathbf{3}$ & OPO-19 & GGTGCACGTT & 60 & 46 \\
\hline
\end{tabular}

Table.2 HPV DNA Identification and Genotyping Result

\begin{tabular}{|r|r|r|r|c|c|}
\hline No. & Sample ID & Source & Origin & HPV Identification & HPV Type \\
\hline $\mathbf{1}$ & MA.109.01 & Cervical Biopsy & Pekanbaru & + & 16 \\
\hline $\mathbf{2}$ & MA.107.02 & Cervical Biopsy & Pekanbaru & + & 16 \\
\hline $\mathbf{3}$ & MA.106.03 & Cervical Biopsy & Pekanbaru & + & N/A \\
\hline $\mathbf{4}$ & MA.105.04 & Cervical Biopsy & Pekanbaru & + & 16 \\
\hline $\mathbf{5}$ & MA.104.05 & Cervical Biopsy & Padang & - & - \\
\hline $\mathbf{6}$ & MA.103.06 & Cervical Biopsy & Pekanbaru & + & 18 \\
\hline $\mathbf{7}$ & MA.102.07 & Cervical Biopsy & Pekanbaru & + & 18 \\
\hline $\mathbf{8}$ & MA.096.08 & Cervical Biopsy & Pekanbaru & + & 18 \\
\hline $\mathbf{9}$ & MA.108.09 & Cervical Biopsy & Pekanbaru & - & - \\
\hline $\mathbf{1 0}$ & MA.060.10 & Cervical Biopsy & Padang & + & 16,18 \\
\hline $\mathbf{1 1}$ & MA.058.11 & Cervical Biopsy & Padang & + & 18 \\
\hline $\mathbf{1 2}$ & MA.056.12 & Cervical Biopsy & Padang & + & 18 \\
\hline $\mathbf{1 3}$ & MA.055.13 & Cervical Biopsy & Padang & + & 16,18 \\
\hline $\mathbf{1 4}$ & MA.054.14 & Cervical Biopsy & Padang & + & - \\
\hline $\mathbf{1 5}$ & MA.092.15 & Cervical Biopsy & Padang & - & 18 \\
\hline $\mathbf{1 6}$ & MA.052.16 & Cervical Biopsy & Padang & + & - \\
\hline $\mathbf{1 7}$ & MA.093.17 & Cervical Biopsy & Pekanbaru & - & 16 \\
\hline $\mathbf{1 8}$ & MA.091.18 & Cervical Biopsy & Padang & + & - \\
\hline $\mathbf{1 9}$ & MA.094.19 & Cervical Biopsy & Padang & - & - \\
\hline $\mathbf{2 0}$ & MA.095.20 & Cervical Biopsy & Pekanbaru & - & + \\
\hline
\end{tabular}


Figure.1 The amplified DNA of HPV using primer MY09/11 (Lane L: 100 bp DNA marker, Lane 1-15 DNA sample (1: MA.109.01, 2: MA.107.02, 3: MA.106.03, 4: MA.105.04, 5: MA.114.05, 6: MA.103.06, 7: MA.084.09,8: MA.084.09, 9:MA.060.10, 10: MA.058.11, 11: MA.056.12, 12: MA.055.13,13:MA.092.15, 14:MA.052.16, 15:MA.093.17)

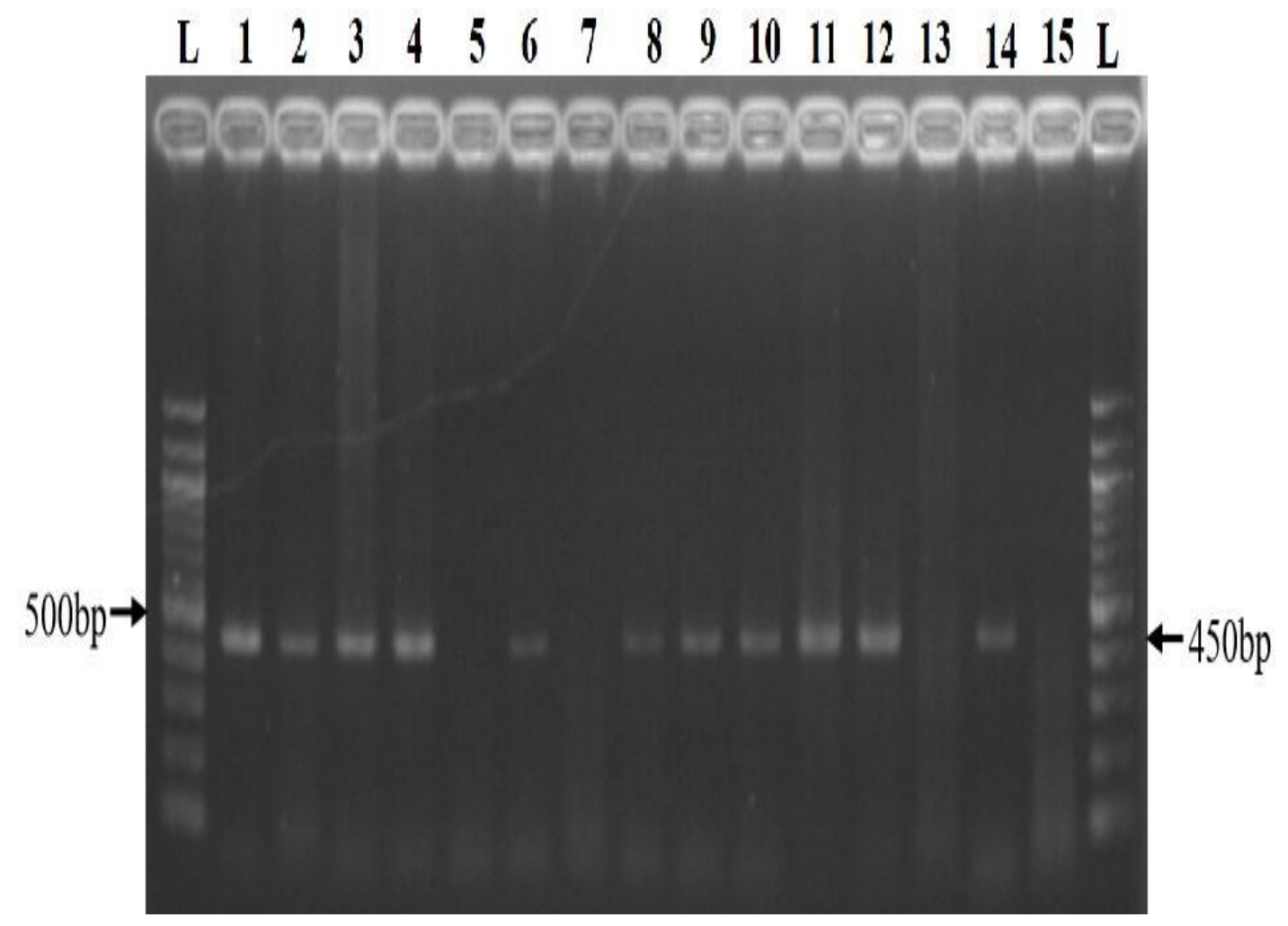

Figure.2 RAPD Fingerprinting of Human papillomavirus Strains. The gel image strengthened by BioNumerics version 6.6 software. (A) OPO-06 primer; (B) OPO-18 primer; (C) OPO-19 primer

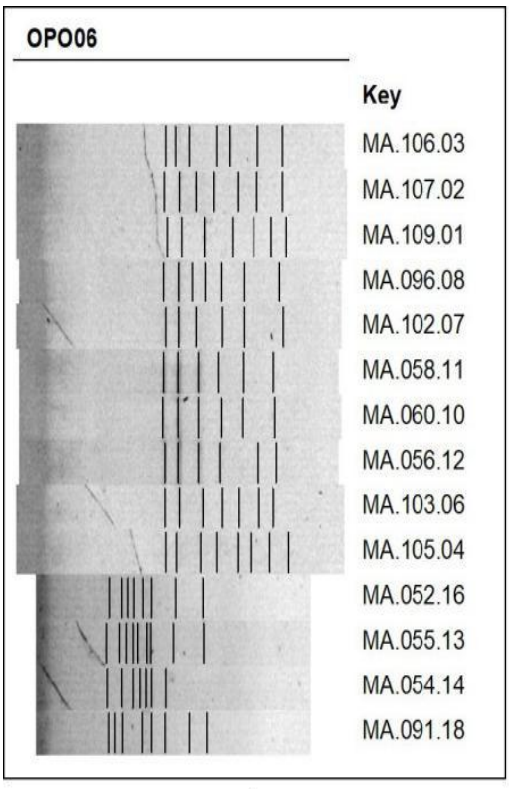

A

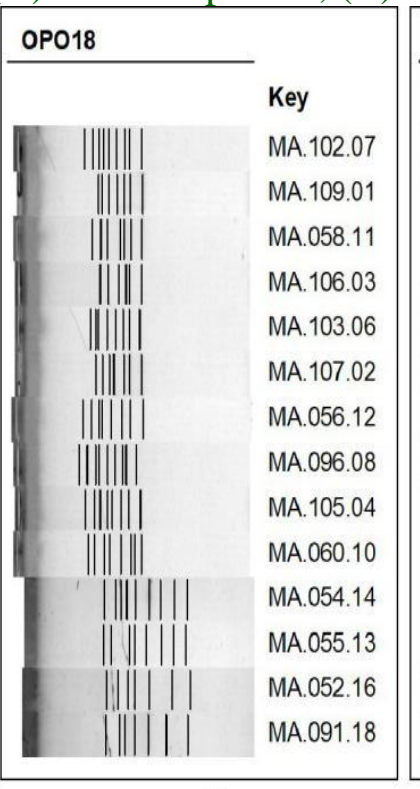

B

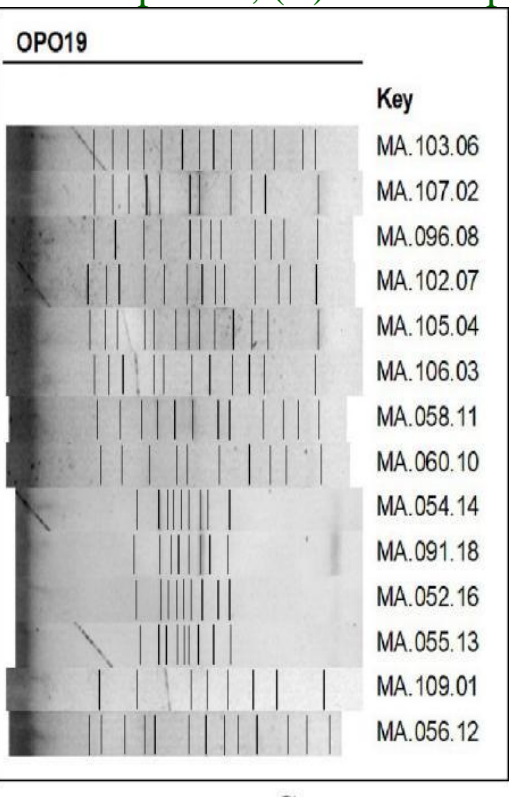

C 
Figure.3 Representative dendrogram showing similarity of 14 Human papillomavirus strains based on the combination RAPD-PCR gel documentation using UPGMA method

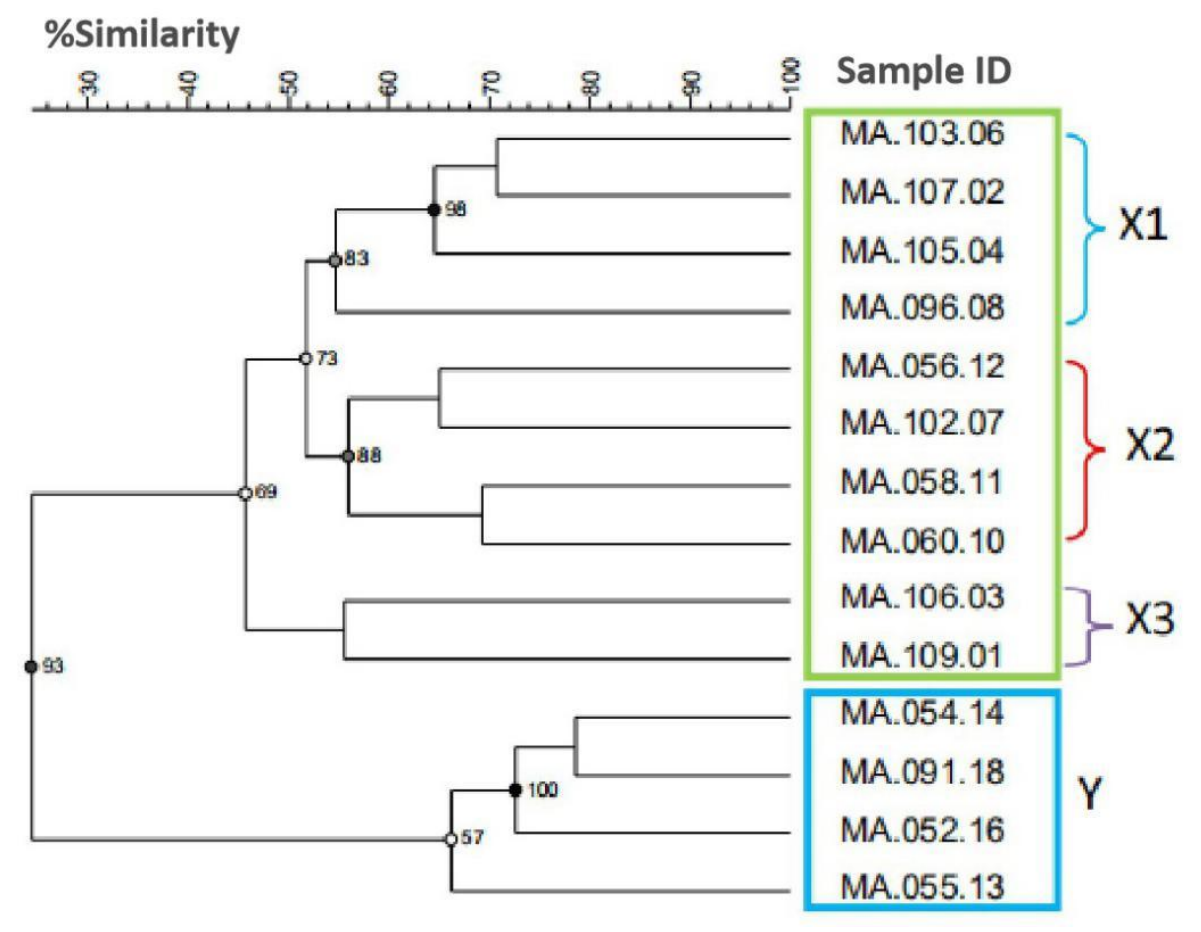

Different result reported by Wang (2018) study in invasive cervical cancer, cervical intraepithelial neoplasia and asymptomatic women in Southeast China. This study reveals HPV 18 is the most prevalent genotype among in the positive cases.

In another study conducted in Ghana, HPV genotype distribution not only discovered high-risk HPV but also low-risk HPV. There is eleven genotype detect in this study, 9 highrisk HPV; HPV-16 (8\%), HPV-35 (5\%), HPV-33/39/-68 (3\%), HPV-52/51/59 (2\%) and HPV-18 (1\%) and 2 Low-risk types; HPV-42(3\%), and HPV-43 (1\%) (Adams et al., 2019). HPV genotypes distribution differs between regions. This difference causes the need for different prevention and therapeutic efforts for each geographic area.

PCR-RAPD amplification of the samples in this study with OPO-6 primers obtained 6-8 fragments, with OPO-18 primers obtained 6-9 fragments, and OPO-19 produces more amplification results than other primers namely 8-13 bands (shown in Figure 2). The size of the bands produced by each primer varies from 250-1500 bp. HPV genetic variation observed from the difference in the number of DNA fragments amplified in each primer.

The result of HPV samples dendrogram using OPO-6, OPO-18, and OPO-19 primer data shown in Figure 3. Based on the dendrogram, samples were divided into two large groups of $\mathrm{X}$ and $\mathrm{Y}$ cluster. In the dendrogram which can be seen in cluster $\mathrm{X}$ were divided into three subgroups named X1, X2, and X3. It can be seen from the dendrogram that cluster $\mathrm{X} 1, \mathrm{X} 2$ came from Pekanbaru and cluster $\mathrm{Y}$ came from Padang, while at cluster X3 came from Padang and Pekanbaru. These suggest that the genetic diversity of HPV is related to geographical regions. According to Heinzel, et al., (1995) that there is a minor correlation between HPV variants with geographic and ethnic origin but it is uncertain whether the 
spread of viral variants occurred during the evolutionary process or related to human ethnic mobility worldwide.

HPV distribution in the world is different. HPV-16 variations can be classified based on phylogenetic and distributed across five continents and in different ethnic groups. These variants include European, Asian, Asian-American, which also North American variants, type 1 African and type 2 African (Terai et al., 2005). For HPV-18, different variants have been defined as AsianAmerican, African, and European variants (Chen et al., 2009).

De Boer, et al., (2004) used the samples of HPV-16 patients with cervical cancer from the Indonesian population, Suriname, and the Netherlands. In Indonesia, the variant occurs at the L1, E7, and E6 regions, and this variant called as Java or Javanese variant because it came from Javanese ethnic. This Javanese variant was found to be positive in the three Suriname samples, this could be due to the migration of the Javanese population to Surinam. In a study conducted by Fadhilah, et al., (2015) showed that HPV type 16, isolated from cervical cancer patients from Bandung which located in one subgroup with HPV from Asia and East Asia, and no Javanese variants were found in the isolates. Thus, ethnic differences, as well as the presence of different genotypes of HPV genes in the Padang and Pekanbaru regions, resulted in differences of HPV genetic sequences.

The dendrogram showed that RAPD cannot be used to distinguish the type of Human papillomavirus. As in cluster $\mathrm{X} 1$, there are two HPV types 18 and two HPV type 16. RAPD used the entire genome for its analysis while HPV is classified as a molecular variant if it has more than $98 \%$ similarity at the L1 sequence of prototype genes (Bernard et al., 2010) and the identification of new HPV genotypes should have a complete isolation genome, indicating $10 \%$ of the diversity of nucleotide sequences in L1 genes isolated from all known genotypes (Villers et al., 2004).

Based on the results of this study, it can be concluded that HPV variation can be influenced by geographical regions. Furthermore, it is desirable to research the molecular variation of HPV using another method, so that it can be used to control HPV infection.

\section{Acknowledgement}

This research was funded by The Ministry of Research and Technology, Indonesia through PMDSU Research Grant number 163/SP2H/LT/DRPM/IV/2019.

\section{References}

Adams, A.R., P. A. Nortey, B.A. Dortey, R.H. Asmah, and E.K. Wiredu. 2019. Cervical Human Papillomavirus Prevalence, Genotypes, and Associated Risk Factors among Female Sex Workers in Greater Accra, Ghana Journal of Oncology. (4): 1-6.

Benard. H.U., R.D. Burk, Z. Chen, K. van Doorslaer, H. Hause, E.M. de Villiers. 2010. Classification of papillomaviruses (PVs) based on 189 amendments. Virology. 401 (1):70-79.

Bray, F., J. Ferlay, I. Soerjomataram, I. Siegel, L.A. Torre, A. Jemal. 2018. Global cancer statistics 2018: GLOBOCAN estimates of incidence and mortality worldwide for 36 cancers in 185 countries. CA Cancer J Clin. 68:394-424.

Camargo, M., S. Leona, R. Sanchez, M. Munoz, E. Vega, M. Beltrana, A.P. Prados, M.E.Patarroyoa,M.A.Patarroyo. 2011. Detection by PCR of human 
papillomavirus in Colombia: Comparison of GP5+/6+ and MY09/11 primer sets. Journal of Virological Methods. (178)1: 68-74.

Chen, Z., R.Desalle, M. Schiffman, R. Herrero, R.D. Burk. 2009. Evolutionary dynamics of variant genomes of human papillomavirus types 18, 45, and 97. Journal Virology. 83(3): 1443-1455.

Coscia, M.F., R. Monno, A. Ballini, R. Mirgaldi, G. Dipalma, F. Pettini, V. Cristallo, F. Inchingolo, C. Foti, D. de Vito. 2015. Human papilloma virus (HPV) genotypes prevalence in a region of South Italy (Apulia).Ann Ist Super Sanita. 51(3): 248-51.

De Boer, M.A., L.A. Peters, M.F. Aziz, B. Siregar, S. Cornain, M.A. Vrede. 2004. Human papillomavirus type 16 E6, E7, dan L1 variants in cervical cancer in Indonesia, Suriname, and The Netherlands. Gynecology Oncology. 94(2): 488-494.

Dunne, E., and L. Markowitz. 2006. Genital Human papillomavirus infection. Clin Infect Dis. 43:2-12.

Erhart, S.M.M., E.R.C. Rivero, M.L. Bazzo, A.S.C. Onofre. 2016. Comparative evaluation of the GP5+/6+, MY09/11 and PGMY09/11primer sets for HPV detection by PCR in oral squamous cell carcinomas. Experimental and Molecular Pathology. 100: 13-16.

Fadhilah, F.R., E. Sahiratmadja, R.Safitri, A.M. Maskoen, H. Susanto. 2015. Phylogenetic Analysis L1 gene Human papilomavirus 16 for patient cervical cancer in Bandung. MKB. 47(3):174178.

Heinzel, P.A, S.Y. Chan SY, L. Ho, M. Oconnor, P. Balaram, M.S. Campo. 1995. Variation of Human papillomavirus type 6 (HPV-6)and HPV-11 genomes sampled throughout the world. Journal Clinical Microbiology. 33(7):1746-1754.
ICO Information Centre on HPV and Cancer. 2017. Human papillomavirus and Related Cancers, Fact Sheet: Indonesia. Barcelona: Institut Catalàd'Oncologia.

Jiang, L., X. Tian, D. Peng, L. Zhang, F.Xie, C. Bi. 2019. HPV prevalence and genotype distribution among women in Shandong Province, China: Analysis of 94,489 HPV genotyping results from Shandong's largest independent pathology laboratory. PLoS ONE 14(1): e0210311.

Marlina, A. Yufri, E.P. Andani, S.S. Densi, G.H. Dewi, Arfiandi, D. Akmal D, Rustini. 2016. Identification of the type of Human papillomavirus (HPV) in patients with, cervical cancer. Jurnal Sains Farmasi \& Klinis. 3(1): 54-63.

Milena, C., S.S. Leona, R. Sanchez, M. Munoz, E. Vega, M. Beltraa, A. PerezPrados, M.E. Patarroyo, M.A. Patarroyoa. 2011. Detection by PCR of human papillomavirus in Colombia: Comparison of GP5+/6+ and MY09/11 primer sets. Journal of Virological Methods. 178: 68-74.

Qu, W., J. Gang, C. Yvette, J.C. Chee, Y.F. Gloria, S.K. Robert, D.B. Robert. 1997. PCR Detection of Human papillomavirus: Comparison between MY09/MY11 and GP51/GP61 Primer Systems. Journal of Clinical Microbiology. 35(6):1304-1310.

Serrano, B., M. Brotons, F.X. Bosch, L. Bruni. 2018. Epidemiology and burden of HPV-related disease. Best Practice \& Research Clinical Obstetrics and Gynaecology. 47: 14-26.

Shikova, I., Todorova, G. Ganchev, V. Kouseva-Dragneva. 2009. Detection and Typing of Human Papillomaviruses by PCR. Biotechnology \& Biotechnological Equipment. 23(1): 877-880.

Sopianti, D.S., A.E. Putra, Y. Aldi, Marlina. 2016. Molecular variation of E5 gene 
Human papillomavirus (HPV) from cervical cancer. Research Journal of Pharmaceutical, Biological and Chemical Sciences. 7(5): 1695-1701.

Terai, M., Z. Chen, L. Fu, R. Herrero, R. Desalle, R.D. Burk. 2005. Diversifying selection in Human papillomavirus type 16 lineages based on complete genome analyses. Virology. 79(11):7014-7023.

Torre, L.A.F. Bray, R.L. Siegel, J. Ferlay, T.J. Lortet, A. Jemal. 2015. Global cancer statistics2012. CA Cancer J Clin. 65(2):87-108.

Venceslau, E.M., M.Z. Mauro, C.M.L. Anna, V.S. Érick, S.C.O. Alexandre, M.M. Claudia, L.S.J. Verônica, B.M.O. Fabiana. 2014. HPV Detection Using Primers MY09/MY11 and GP5+/GP6+ In Patients with Cytologic and/or Colposcopic Changes. Brazilian Journal of Pathology and Laboratory Medicine. 50(4):280-285.

Villers, E.M., C. Fauquent, T.R. Broker, H.U. Benard, H. zurHausen. 2004. Classification Human papillomavirus. Virology. 32:16-24.

Wang, X., Y. Zeng, X. Huang, and Y. Zhang. 2018. Prevalence and Genotype Distribution of Human Papillomavirus in Invasive Cervical Cancer Cervical
Intraepithelial Neoplasia, and Asymptomatic Women in Southeast China. BioMed Research International. 2: $1-10$

Welsh, J., and M. McClelland. 1990. Fingerprinting genomes using PCR witharbitrary primers. Nucleic Acids Res. 18:7213-7218.

Williams, J. G. K., A.R. Kubelic, K.J. Livak, J.A. Rafalski, S.V. Tingey. 1990. DNA Polymorphisms amplified by arbitrary primers are usefull as genetic markers. Nucleic Acids Res. 18: 6531-6535.

Wolday, D., M. Derese, S. Gebressellassie, B. Tsegaye, W. Ergete, Y. Gebrehiwot, O. Caplan, D. G. Wolf, and S. Maayan. HPV genotype distribution among women with normal and abnormal cervical cytology presenting in a tertiary gynecology referral Clinic in Ethiopia. Infect Agent Cancer. 2018; 13: 28.

Wuriningtyas, L.C., D.R. Pawarti, A.C. Ramdhoni. 2014. Phylogenetic Human papillomavirus (HPV) type 6 and type 11 in patient recurrent respiratory papillomatosis. Oto Rhino Laryngologica Indonesiana. 44(1): 5262.

\section{How to cite this article:}

AyuNovita Trisnawati, Annisa Fatharani, Florence Clay Mora, Yufri Aldi, AndaniEka Putra, Yoke Kqueen Cheah and Marlina. 2020. Random Amplified Polymorphic DNA (RAPD) Analysis of Human papilloma virus Isolated from Cervical Cancer Patient. Int.J.Curr.Microbiol.App.Sci. 9(04): 33-42. doi: https://doi.org/10.20546/ijcmas.2020.904.006 